\title{
SELECCIÓN DE FOTOGRAFÍAS DE ESTUDIANTES DE PRIMER SEMESTRE DE ARTES AUDIOVISUALES UNAB - TALLER DE REALIZACIÓN
}

Dirigido por el profesor Manuel José Jaimes - Correo electrónico: mjaimesg@unab.edu.co 


\section{SELECCIÓN DE FOTOGRAFÍAS DE ESTUDIANTES DE PRIMER SEMESTRE DE ARTES AUDIOVISUALES UNAB- TALLER DE REALIZACION}

Al abrir los ojos descubrimos la mirada, pero solo podemos ver cuando abrimos el corazón.

En la primera aproximación que hacen a la imagen y la representatividad del mundo, los estudiantes del programa de Artes Audiovisuales de la Universidad Autónoma de Bucaramanga son invitados a emprender un viaje hacia algún destino cercano de la región, este desplazamiento es solo una excusa para movilizar también su mirada y controvertir la forma en la que cotidianamente leen el mundo, los jóvenes que están siempre tan saturados de información visual y grafica, deben reinventarse la forma de ver para poder entender y descifrar el mundo a través de las imágenes que ahora ellos capturan.

A continuación encontramos una selección de fotografías que corresponden a este ejercicio y que nos revelan con mucha nitidez que a pesar de la contaminación visual que el mundo actual supone, el estudiante es capaz de detenerse a mirar con atención lo que la realidad le cuenta y adicionalmente puede transformar el conocimiento técnico fotográfico en una obra de gran significado y belleza. 


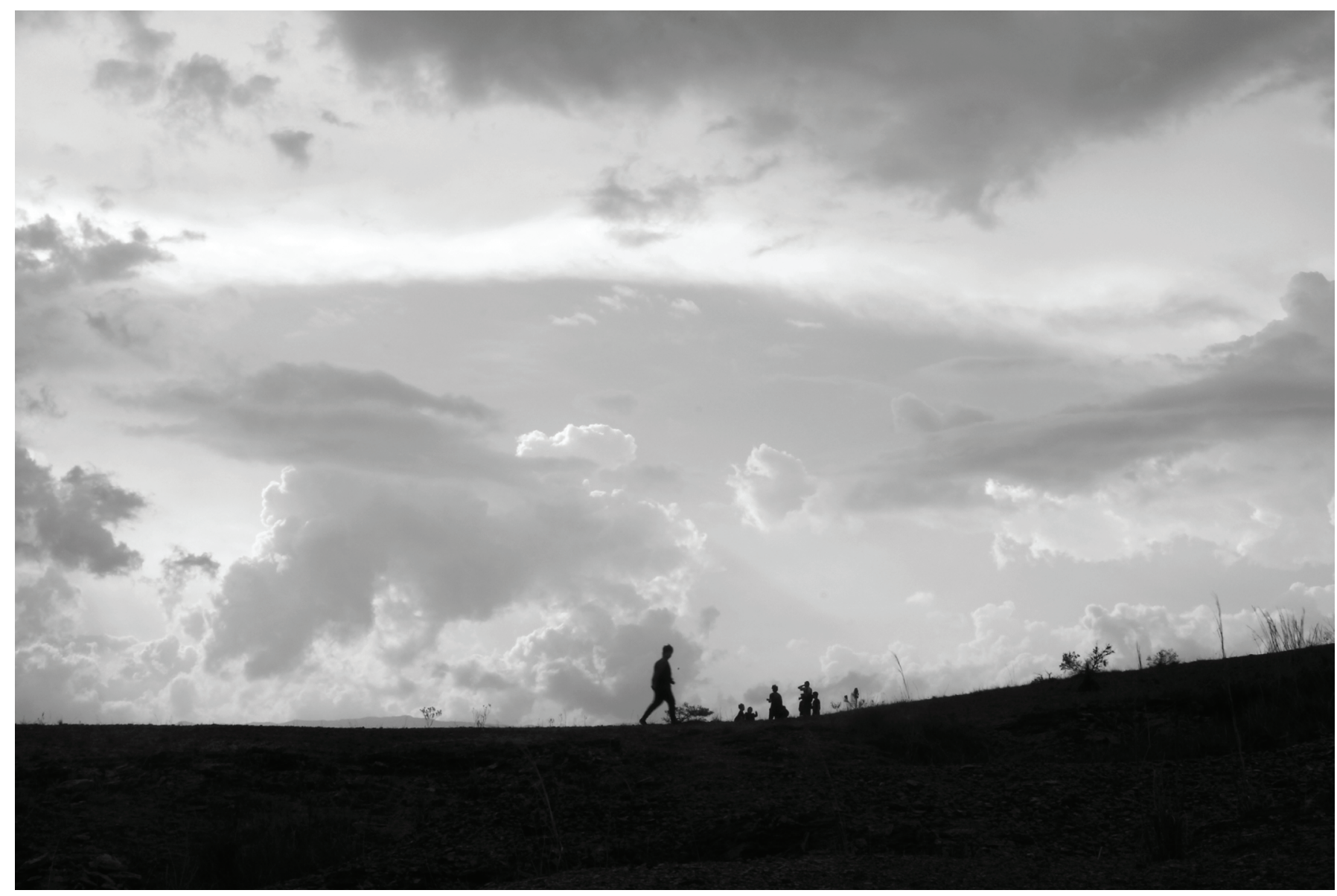

Ángela Duarte 


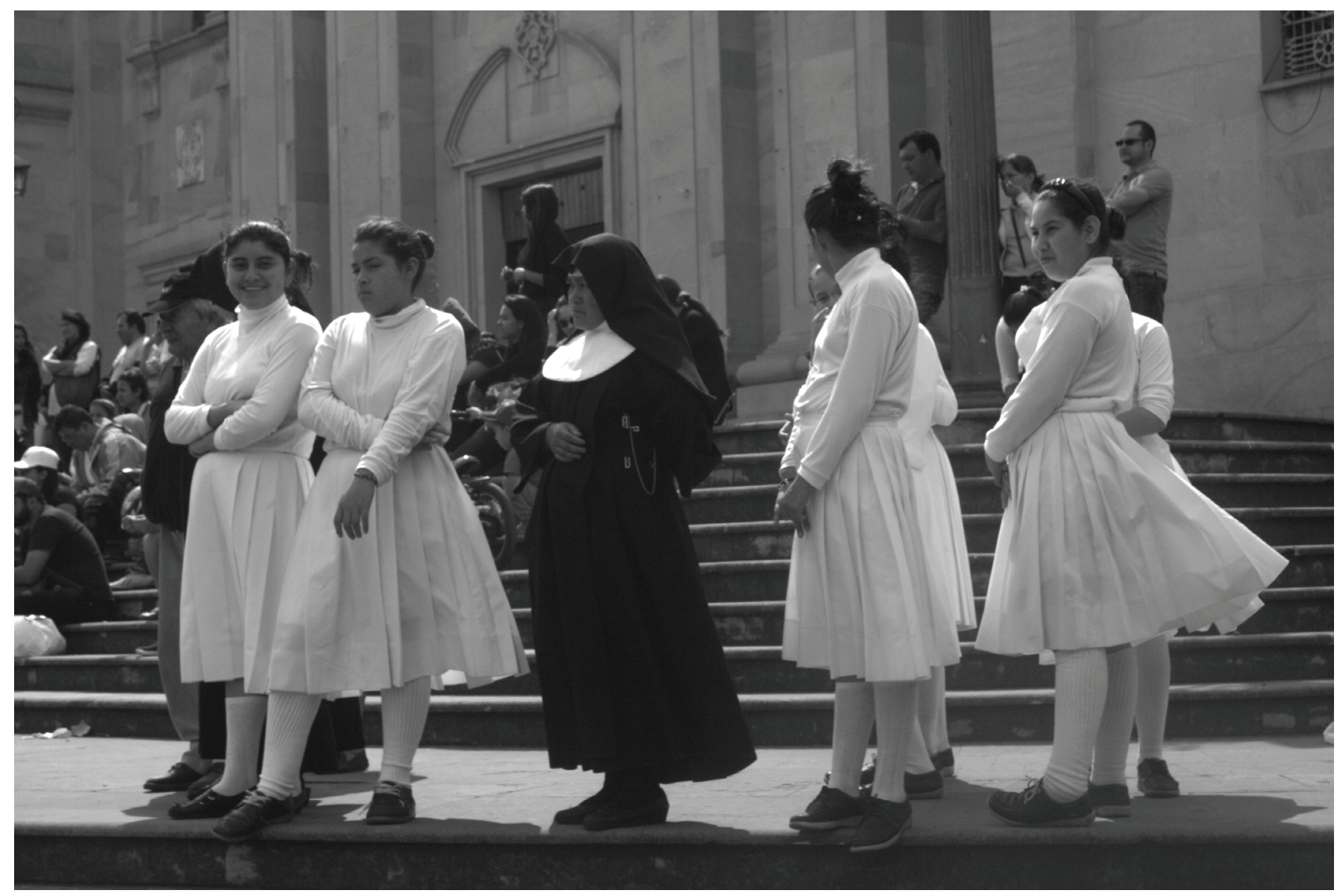

Alejandra Franco 


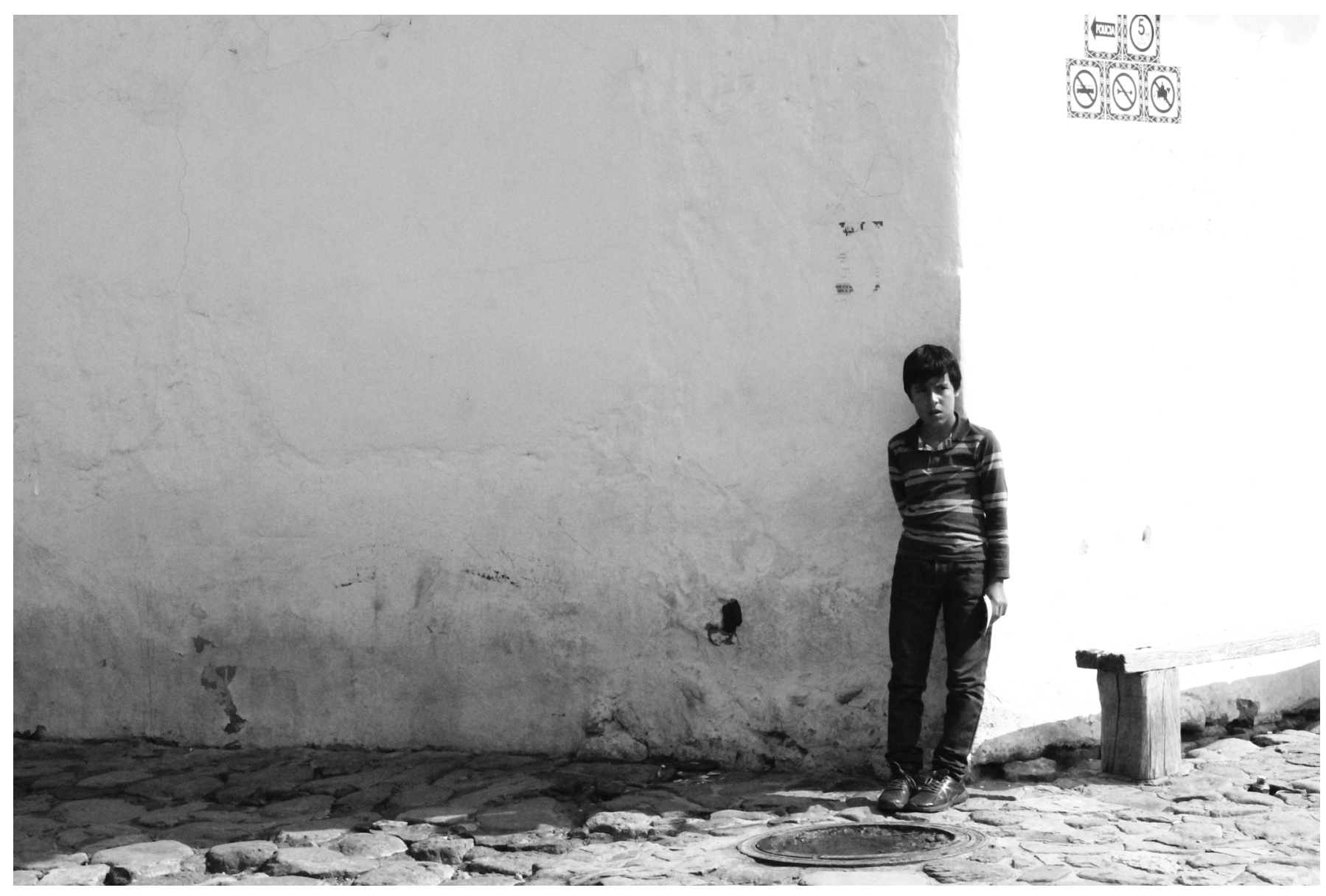

Natalia Ariza 


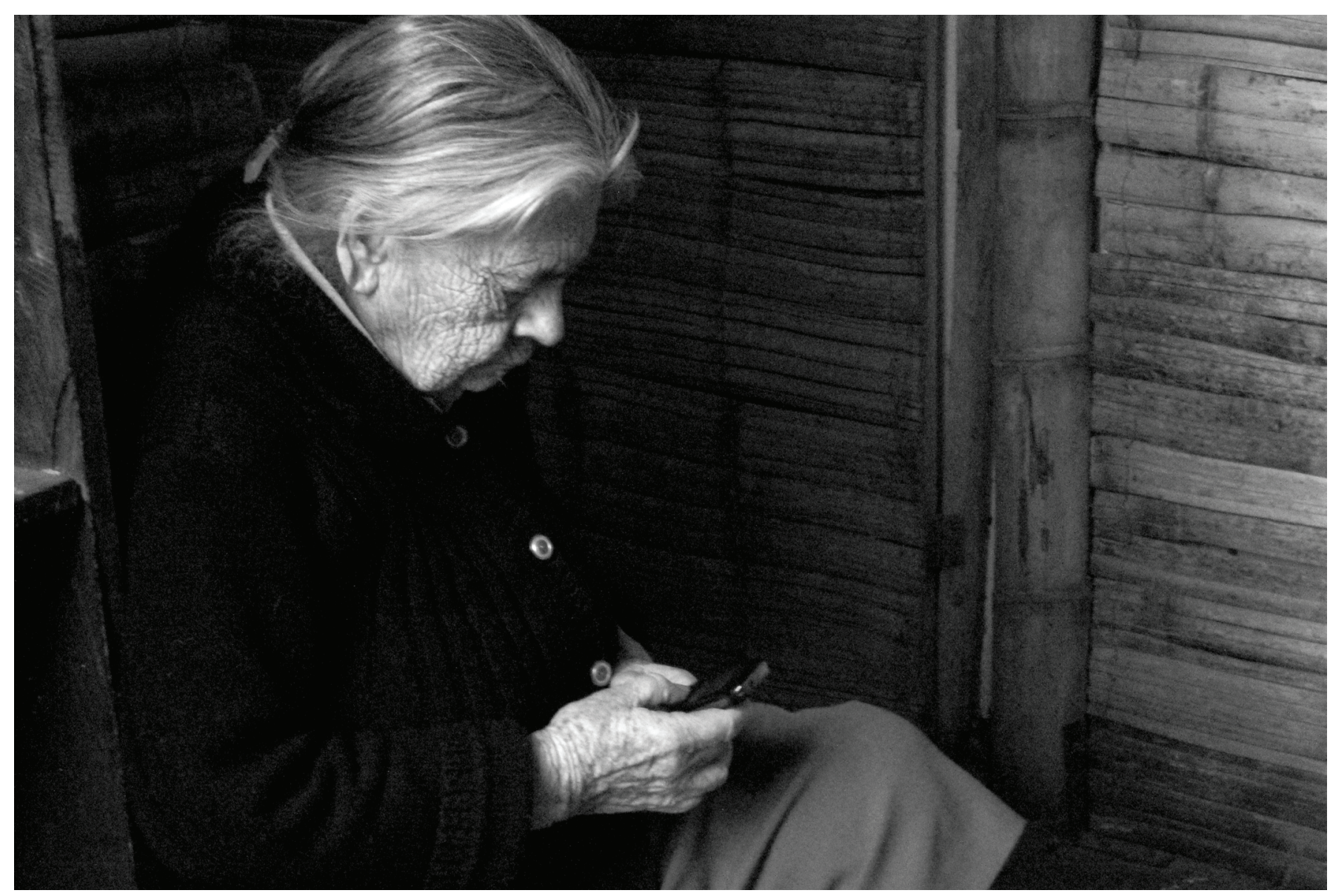

Andrés Valbuena 


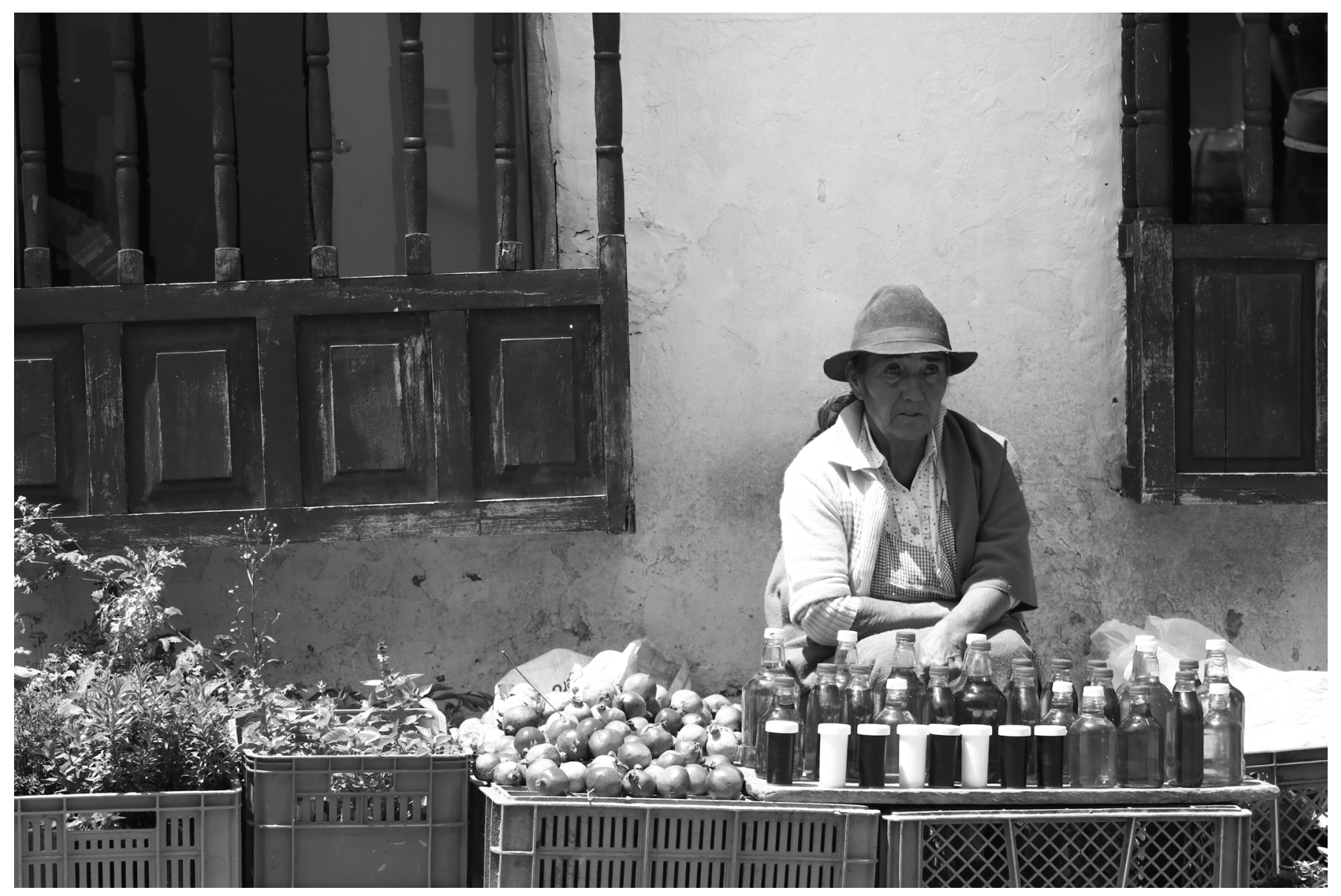

Sebastián Peña 


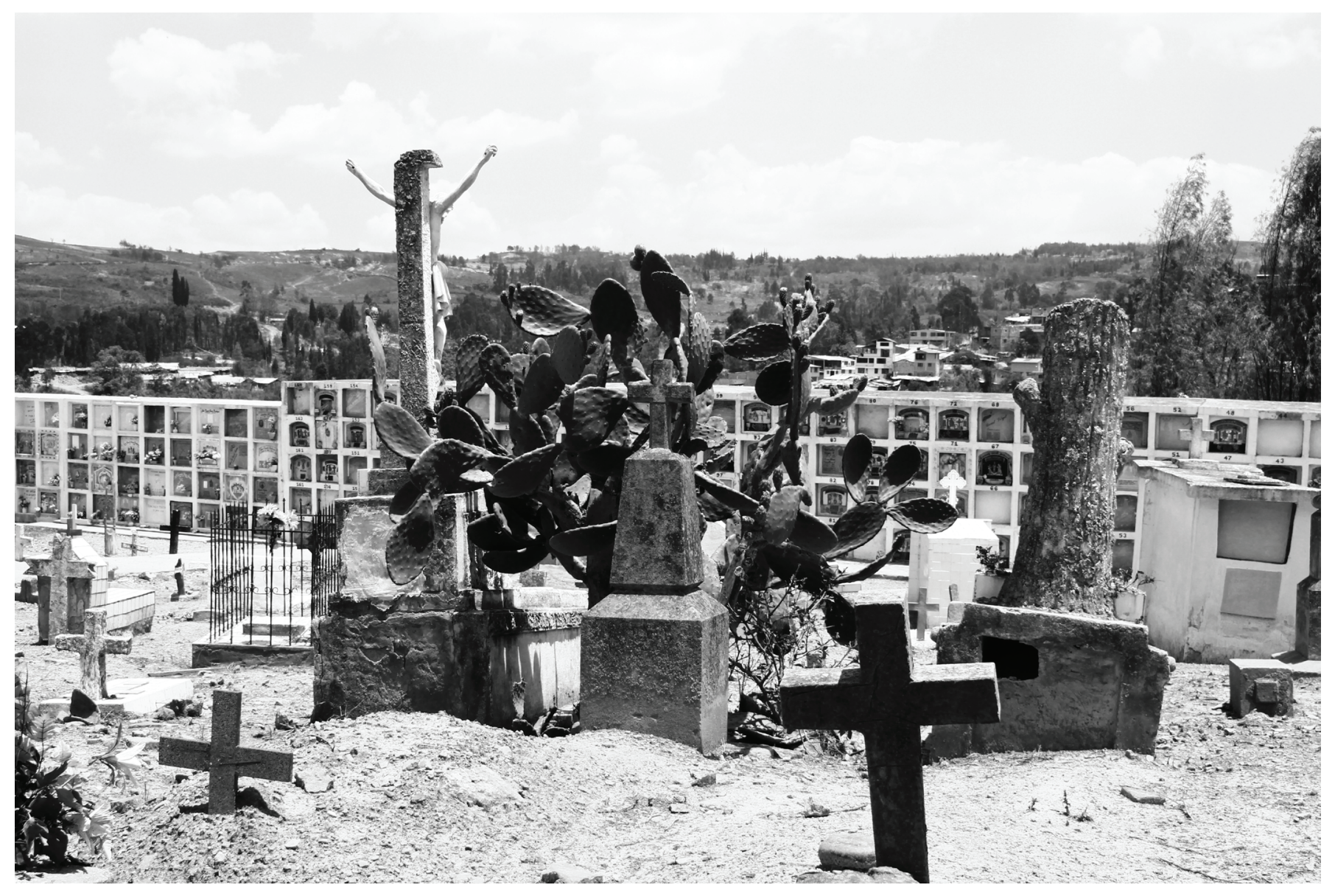

Mariana Vanegas 


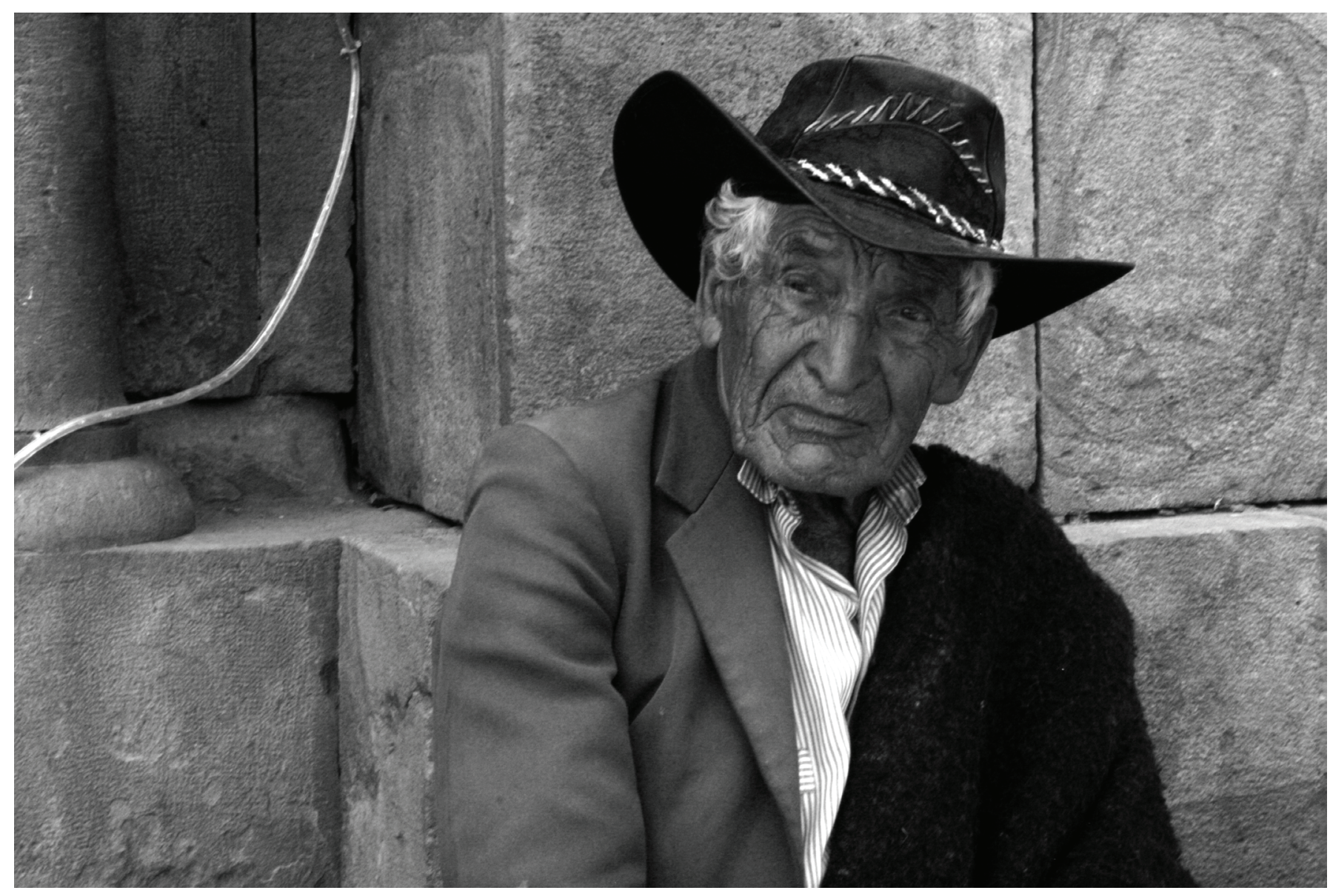

Alejandra Franco 